\title{
Polybrominated Biphenyls in Lactating Michigan Women: Persistence in the Population
}

\section{F. DeWolfe Miller, ${ }^{1}$ Lawrence B. Brilliant, ${ }^{1}$ and Richard Copeland ${ }^{2}$}

1School of Public Health, University of Michigan, 109 Observatory St., Ann Arbor, MI 48109 and 'Environmental Research Group, Inc.,

Ann Arbor, MI 48104

Polybrominated biphenyls (PBB) were inadvertently introduced into livestock feed in Michigan in 1973, resulting in widespread contamination of the state's food supply. Details of this unfortunate incident have been extensively documented (Carter 1976; Meester 1979). Approximately 12 months after the spill, several reports demonstrated the presence of $\mathrm{PBB}$ in human tissues including fat and blood serum as well as in breast-milk specimens (Brilliant et al. 1978; Landrigan 1980). Brilliant et al. (1978) described the distribution of $\mathrm{PBB}$ body burdens among a random sample of lactating women, and estimated that as many as 97 per cent of Michigan residents could be expected to have detectable levels of PBB. The distribution of PBB body burdens was skewed geographically, higher levels being found in the more populous lower peninsula. other studies have suggested that levels of $\mathrm{PBB}$ in the Michigan population decrease with increasing distance from contaminated farms (Wolff et al. 1978) and appear to be higher in males and children (Wolff et al. 1982). There are insufficient data available to describe agespecific distributions.

Kimbrough et al. (1978) and Matthews et al. (1977) have found that PBB concentration in animal tissues decreases very slowly over time, if at all. Serial testing for $P B B$ in one lactating woman in Michigan revealed that $\mathrm{PBB}$ was found to vary in a narrow range between 0.1 and $0.2 \mathrm{ppm}$ in breast-milk during a threemonth period without any significant downward trend (Brilliant et al. 1978). The lipophilic and structurally stable nature of $\mathrm{PBB}$ suggests that tissue concentrations may remain high for long periods. Polychlorinated biphenyl (PCB), a chemical analogue of $P B B$, appears to persist in tissues for indefinite periods (Wickizer et al. 1981). Paired studies among farmers who had been shown to have very high serum $\mathrm{PBB}$ levels suggest long term maintenance of $\mathrm{PBB}$ in body fat (Wolff et al. 1979). 
More recently, Kreiss et al. (1982) examined matched serial specimens from a sample of over 800 Michigan residents at three intervals, each one year apart, and found a decrease of $0.001 \mathrm{ppm}$ after the first and second years. Changes in PBB body burden occur as a result of several interrelated factors including continued exposure to PBB, partitioning boundaries between various body stores of PBB, fatty acid metabolism, and excretion in the feces (Ester et al. 1982).

The present study provides additional insight into the persistence of $\mathrm{PBB}$ at the population level from observations over a continuous 32 -month period on a large sample of lactating Michigan women.

\section{METHODS AND MATERIALS}

In response to the finding that nearly all nursing mothers in Michigan were likely to have detectable levels of $\mathrm{PBB}$ in their breast-milk (Meester 1979), the Michigan Department of Public Health announced that breast-milk specimens voluntarily submitted by nursing women would be analyzed for $P B B$ at the expense of the state of Michigan. The objective was to provide information to concerned women on their own PBB levels, leaving each woman and her personal doctor responsible for any subsequent decision to breast feed. The announcement was made through appropriate media channels and directly to all Michigan-licensed physicians in December, 1976, approximately three- and one-half years after the accidental contamination of the Michigan food chain with PBB.

Specimens of breast-milk were collected, shipped to the Environmental Research Group, Inc., labeled and analyzed for PBB as described previously (Wickizer et al. 1981). Only one specimen per person was analyzed. All specimens received during the 32 -month period (May 1,1976 to December 31,1978 ) were analyzed and defined the total study population of 2986 women. Age, current residence in Michigan, and the date of specimen collection were recorded.

\section{RESULTS AND DISCUSSION}

There were 2986 breast-milk specimens submitted to be analyzed for PBB. Each specimen was from a nursing mother residing in the state of Michigan between May 1976 and December 1978. The mean age of these female respondents was 28 , ranging from 17 to 44 years.

Women reported living at their current addresses for an average of 13 years (range $=1$ to 39 ). It cannot be determined if an individual participant lived at 
another address in Michigan or elsewhere prior to her current residence.

Specimens were received throughout the 32-month surveillance period. The number of specimens received increased sharply each month until 15 months after the program had started; at this point, there was a gradual decline (Fig. 1). The peak of response may reflect public awareness or concerns about exposure to PBB.

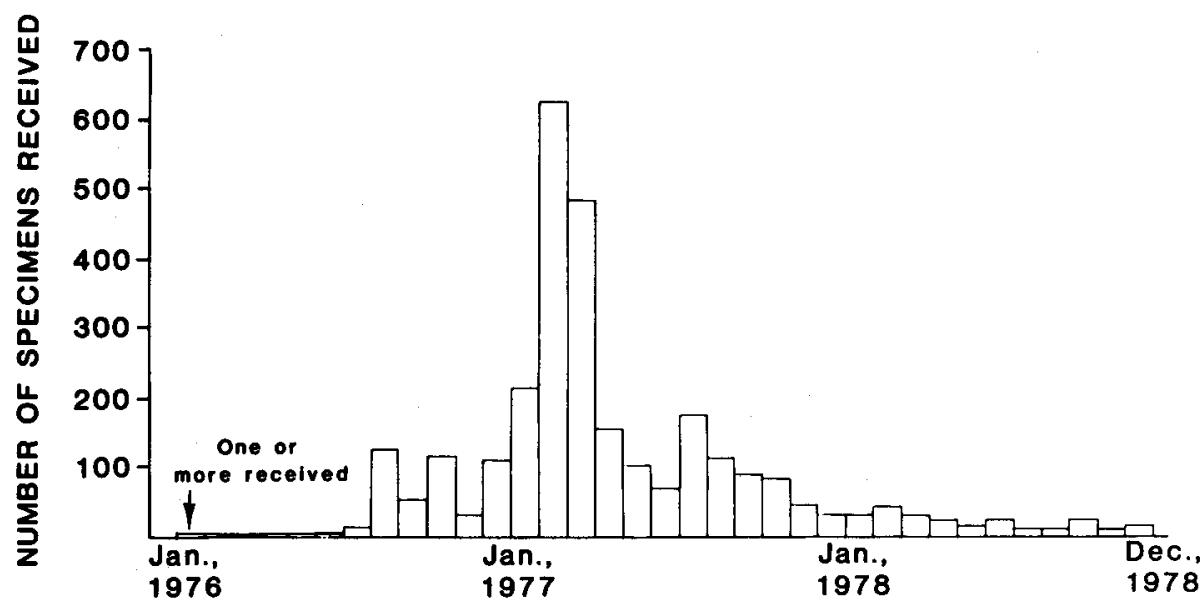

MONTH

Figure 1. Number of breast-milk specimens submitted for PBB analysis by month $(1976-1978)$ in Michigan.

PBB concentration in breast-milk samples ranged from nondetectable $(342$ cases) to $2 \mathrm{ppm}$ with a mean of 0.097 ppm. The distribution of $P B B$ was skewed toward the lower concentrations with a median value of $0.06 \mathrm{ppm}$. Log transformation normalized the skewed shape of the data indicating that the most representative mean was the geometric mean of $0.1 \mathrm{ppm}$.

The large sample size provided a detailed picture of PBB distribution in Michigan by county. Fig. 2 shows that the counties with PBB geometric mean concentrations greater than or equal to $0.5 \mathrm{ppm}$ tended to be in the central western portion of the state and overlapped the area where the original spill occurred. Concentrations of PBB decreased from east to west in the Lower Peninsula and west to east in the Upper Peninsula. This pattern is consistent with anecdotal and previously published reports (Carter 1976; Meester 1979; Wolff et al. 1982). Table 1 shows the distribution of $\mathrm{PBB}$ in the Upper and Peninsulas. Proportionally more women had higher $\mathrm{PBB}$ values in the Lower Peninsula. 


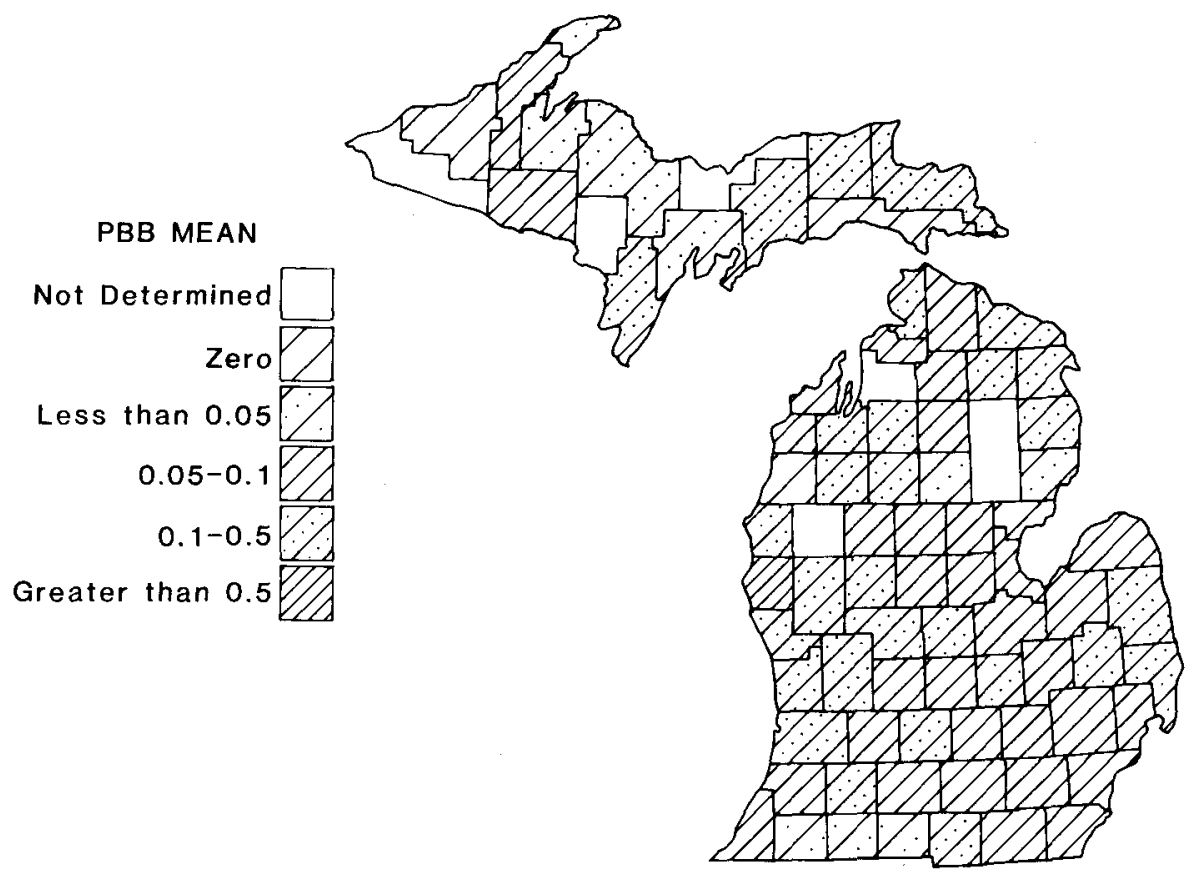

Figure 2. Distribution of mean PBB concentration in breast-milk by county in Michigan (1976-1978) in parts per million.

Table 1. Distribution of PBB in Human Breast-Milk Specimens in Michigan

\begin{tabular}{ccc}
\hline $\begin{array}{c}\text { PBB range } \\
(\text { ppm })\end{array}$ & $\begin{array}{c}\text { Upper Peninsula } \\
\text { number }(\%)\end{array}$ & $\begin{array}{c}\text { Lower Peninsula } \\
\text { number }(\%)\end{array}$ \\
Not detectable & $11(32.1)$ & $331(11.6)$ \\
$<0.05$ & $9(26.5)$ & $728(25.6)$ \\
0.05 to 0.1 & $5(14.7)$ & $921(32.3)$ \\
0.1 to 0.5 & $8(23.5)$ & $824(28.9)$ \\
$>0.5$ & $1(2.9)$ & $44(1.5)$ \\
\hline
\end{tabular}


As shown in Fig. 3, it appeared that the proportion of specimens with detectable levels of PBB declined slightly over time; a regression using the least squares method demonstrated a significant negative correlation over the 32-month period of surveiliance ( $r=$ $-0.41 \quad p=0.02)$. A linear extrapolation of Fig. 3 suggested that slightly less than half of breast-milk specimens ( 47 per cent) would still have detectable levels of PBB by the year 2000.

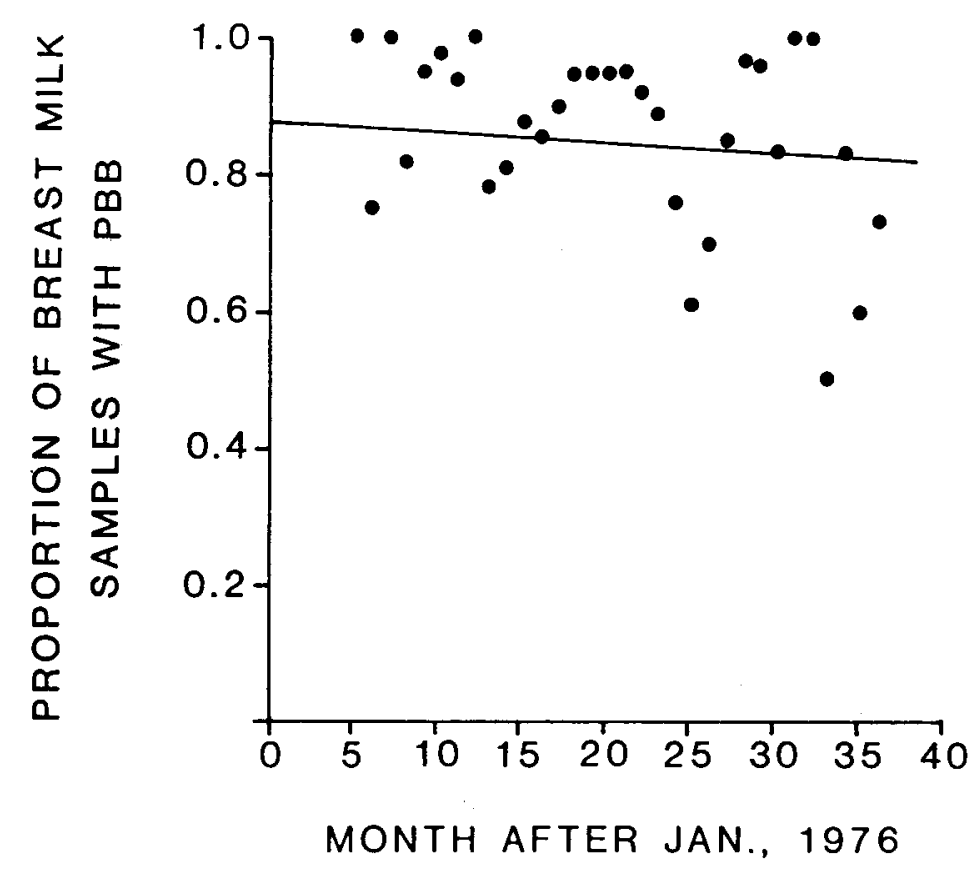

Figure 3. Proportion of specimens with a detectable PBB concentration ( 0.05 ppm or greater) by month of testing. The regression line was fitted by the least squares method $(r=-0.41 \quad p=0.02)$

The proportion of fat in breast-milk was found to vary from specimen to specimen and to have a positive correlation with $\mathrm{PBB}(\mathrm{p}<0.001)$; changes in fat content were examined as one possible explanation for these trends in PBB. The concentration of fat in breast-milk specimens was independent of the date of specimen collection $(p=0.07)$; therefore, changes in breast-milk 
fat do not provide an explanation for the observed downward trend.

Earlier response by women from counties with greater $\mathrm{PBB}$ contamination would provide another explanation for this trend. This would be consistent with a higher degree of publicity, awareness, and concern among such women. To control for the timing of response by women from different counties, an analysis of covariance was performed. This analysis tested for a trend over time in $\mathrm{PBB}$ concentration within each county where there were at least five breast-milk specimens. There were 50 such counties; of these only one demonstrated a significant decrease $(\mathrm{p}<0.05)$ in PBB breast-milk concentration over time. Given the number of comparisons made, it is accurate to report that $P B B$ was not declining. As suggested above, it was the earlier response from more contaminated counties and the later response from less contaminated counties that explained the apparent time trend.

We here report a geographic gradient in the $\mathrm{PBB}$ of breast-milk from 2986 self-selected Michigan women; highest levels were found nearest the original spill. After adjustment for county of residence, PBB concentration did not appear to be decreasing significantly over time.

This self-selected sample of 2986 women represents less than 2 per cent of the estimated 171,000 mothers in the state who would have been eligible for free testing during the study period. The sample, however, is very large and includes women from almost 80 per cent of Michigan's counties. Women from the affected areas of Michigan were expected to respond with greater frequency than women who resided in less affected areas of the state. Other women who suspected or feared higher than "normal" levels of PBB contamination in their breastmilk were also expected to respond with increased frequency. Both factors may systematically bias population estimates of overall PBB concentrations upwards. They are unlikely to affect secular trends within the sample.

There is evidence that $\mathrm{PBB}$ concentrations in body fat are very stable (Wolff et al. 1979). Paired serial adipose specimens from individuals did not significantly change over a period of one year after $P B B$ exposure was removed (Wolff et al. 1979). However, when serum specimens were monitored for $P B B$ concentration over a one- or two-year period, decreases were detected (Kreiss et al. 1982). Transport of PBB from adipose tissue to serum or other tissues may be occurring over fairly long periods, but the rates of transfer remain 
to be described. Presence of PBB in women appears sufficient to expose the fetus (ESTER et al. 1982). Both such previous work and data reported here suggest that individual decrements in body burdens of PBB are likely to be minimal.

A different dynamic model for $P B B$ persistence in the population is conceivable. Using a vocabulary usually reserved for infectious disease transmission, we can term the exposure of $\mathrm{PBB}$ in Michigan food a common source "outbreak" with on-going "transmission" through contaminated food. After the Michigan food chain had been cleared of $P B B$ in 1977, the only person-to-person "transmission" has been through breast-milk and placental transfer. Thus, from an epidemiological perspective, the exposure was more or less finite in time. The immigration of unexposed individuals should eventually "dilute" the overall mean concentration of PBB in the Michigan population. Similarly, because PBB is transmitted to offspring, such transmission (albeit undesirable) will produce the same effect. The lack of a substantial decline in PBB during the period of this study suggests that such "dilution" did not occur during the 32-month period of data collection. Future studies may detect lower mean PBB concentrations as further immigration and pregnancies exert a population influence.

The concentration of PBB observed in this study was, for the most part, consistent with other reports (Brilliant et al 1978; Wolff et al. 1979). Brilliant et al. (1978) described a median of 0.068 ppm PBB with a range from undetectable to $1.2 \mathrm{ppm}$ in a random sample of women lactating during 1976. That estimate was essentially identical to the median reported here, i.e., $0.060 \mathrm{ppm}$. Wolff et al. (1982) analyzed adipose tissue from a random sample of Michigan residents two years later, in 1978, and reported a median concentration of $0.199 \mathrm{ppm}$. Adipose tissue partitions slightly more PBB than breast-milk (1.01:1) (Brilliant et aí. 1978); furthermore, the higher median value may reflect differences in the age and sex of the sample, as children and adult males have consistently higher concentrations than adult females (Wolff et al. 1982). In addition, the mean breast-milk fat content of specimens analyzed here was about $1 \mathrm{gram} / 100 \mathrm{ml}$ lower than that generally observed (Wickizer et al. 1981); this was probably due to the collection of fore milk which has a lower fat concentration than hind milk. The concentration of PBB, a strongly lipophilic compound, was associated with the fat concentration in breast-milk; thus, the lower content of fat in the fore milk may have somewhat reduced $\mathrm{PBB}$ concentrations. 
The attendant exposure of infants to PBB and PCB as well as other important chemicals by breast-feeding will apparently continue for at least several decades. Breast-milk monitoring continues to provide a rapid, noninvasive, and widely acceptable method for the surveillance of $P B B$ and other halogenated hydrocarbons in populations.

Acknowledgements. We thank the nursing mothers who provided breast-milk specimens and the Environmental Research Group, Inc. which carried out the chemical analysis of PBB levels. We thank T.M. Wickizer, G. Brilliant, R. Tilden, and $M$. Zebrowski for help in data analysis and J.G. Joseph for reviewing the manuscript.

\section{REFERENCES}

Brilliant LB, Van Amburburg G, Isbister J (1978) Breast-milk monitoring to measure Michigan's contamination with polybrominated biphenyls. Lancet i i: 643-646

Carter LJ (1976) Michigan's PBB incident: Chemical mix-up leads to disaster. Science 192:240-243

Ester JT, Humphrey HEB, Kimbrough RD (1982) Partitioning of polybrominated biphenyls (PBBs) in serum, adipose tissue, breast milk, placenta, cord blood, biliary fluid and feces. Arch Environ Hlth $38: 47$

Kimbrough RD, Burse VW, Liddle Ja (1978) Persistent liver lesions in rats after a single oral dose of polybrominated biphenyls (Fire-Master FF-1) and concomitant $\mathrm{PBB}$ tissue levels. Environ Hlth Perspect $23: 265-273$

Kreiss K, Roberts C, Humphery HB (1982) Serial BBB levels, $P C B$ levels, and clinical chemistries in Michigan's PBB cohort. Arch Environ Hlth 37:141

Landrigan PJ (1980) General population exposure to environmental concentrations of halogenated biphenyls. In: Kimbrough RD (ed) Halogenated byphenyls, terphenyls, naphthalen, dibenxodioxins and related products. New York: Elsevier North-Holland Inc. pp 267-286

Matthews HB, Kato S, Morales NM, Tuey DB (1977) Distribution and excretion of $2,4,5,2^{\prime}, 4^{\prime}, 5^{\prime}$ hexabrombiphenyl, the major component of fire master (BP-6). Toxicol Environ Hlth 3:599-605 
Meester WD (1979) The effects of polybrominated biphenyls on man: The Michigan PBB disaster. Vet Hum Toxicol 21:231-235

Wickizer TM, Brilliant LB, Copeland R, Tilden R (1981) Polychlorinated biphenyl contamination of nursing mother's milk in Michigan. Am J Pub Hlth 71:132-137

Wolff MS, Maymes N, Anderson HA, Selikoff IJ (1978) Family clustering of $\mathrm{PBB}$ and $\mathrm{DDE}$ values among Michigan dairy farmers. Environ Hlth Perspect $23: 315-319$

Wolff, MS, Anderson HA, Rosenman KD, Selikoff IJ (1979) Equilibrium of polybrominated biphenyl (PBB) residues in serum and fat of Michigan residents. Bull Environ Contam Toxicol 21:775-781

Wolff MS, Anderson HA, Selikoff IJ (1982) Human tissue burdens of halogenated aromatic chemicals in Michigan. J Am Med Assoc 247:2112-2216

Received July 25, 1983; Accepted August 22, 1983 